\title{
BMJ
}

\section{Preventing childhood obesity: two year follow-up results from the Christchurch obesity prevention programme in schools (CHOPPS)}

\author{
Janet James, health promotion specialist nurse, ${ }^{1}$ Peter Thomas, professor of health care statistics and \\ epidemiology, ${ }^{3}$ David Kerr, consultant physician²
}

${ }^{1}$ Bournemouth Diabetes and

Endocrine Centre, Royal

Bournemouth Hospital,

Bournemouth, BH7 7DW

${ }^{2}$ Bournemouth Diabetes and

Endocrine Centre and Centre of

Postgraduate Medical Research

and Education, Bournemouth

University

${ }^{3}$ Centre of Postgraduate Medical

Research and Education,

Bournemouth University and

Dorset Research and

Development Support Unit,

Poole Hospital

Correspondence to: J James

janet.james@rbch.nhs.uk

doi:10.1136/bmj.39342.571806.55

\section{ABSTRACT}

Objective To assess the long term effects of an obesity prevention programme in schools.

Design Longitudinal results after a cluster randomised controlled trial.

Setting Schools in southwest England.

Participants Of the original sample of 644 children aged 7-11, 511 children were tracked and measurements were obtained from 434 children three years after baseline. Intervention The intervention was conducted over one school year, with four sessions of focused education promoting a healthy diet and discouraging the consumption of carbonated drinks.

Main outcome measures Anthropometric measures of height, weight, and waist circumference. Body mass index (BMI) converted to z scores (SD scores) and to centile values with growth reference curves. Waist circumference was also converted to z scores (SD scores).

Results At three years after baseline the age and sex specific BMI z scores (SD scores) had increased in the control group by 0.10 (SD 0.53 ) but decreased in the intervention group by -0.01 (SD 0.58), with a mean difference of 0.10 ( $95 \%$ confidence interval -0.00 to 0.21 , $\mathrm{P}=0.06$ ). The prevalence of overweight increased in both the intervention and control group at three years and the significant difference between the groups seen at 12 months was no longer evident. The BMI increased in the control group by 2.14 (SD 1.64) and the intervention group by 1.88 (SD 1.71), with mean difference of 0.26 $(-0.07$ to $0.58, P=0.12)$. The waist circumference increased in both groups after three years with a mean difference of 0.09 ( -0.06 to $0.26, P=0.25)$.

Conclusions These longitudinal results show that after a simple year long intervention the difference in prevalence of overweight in children seen at 12 months was not sustained at three years.

\section{INTRODUCTION}

Childhood overweight and obesity is an international problem, with $10 \%$ of school age children estimated to be overweight. ${ }^{12}$ In the United Kingdom, obesity in children increased from $9.9 \%$ in 1995 to $13.7 \%$ in $2003 .^{3}$ Although the UK government has set an ambitious target of stopping this escalating trend by 2010 , a recent publication forecasts that there could be further increases, with $19 \%$ of boys and $24 \%$ of girls aged under 10 predicted to be obese by $2010 .{ }^{4}$

Numerous studies have been conducted with the aim of preventing obesity in children and young adults, many of which have been based in schools. ${ }^{56}$ A recent revised Cochrane review ${ }^{7}$ considered 22 studies, including 10 long term and 12 short term projects, most of which were school based and focused on multiple interventions, while some had more specific approaches. The review reported that in most cases the interventions did not significantly affect of the weight of the children. One reason for the disappointing results might have been that most of the projects were too short in duration to be effective.

One school based intervention described by the Cochrane review as a good quality randomised controlled trial was the Christchurch obesity prevention project in schools (CHOPPS), also sometimes referred to as the "ditch the fizz" project. This project was started in August 2001 and was completed over one school year. It was based in six junior schools in southern England and included children aged 7-11. The intervention focused on discouraging children from consuming carbonated drinks and involved one hour of additional health education during each of the four school terms. The intervention is described in more detail elsewhere. ${ }^{8}$ The original project produced a modest reduction in the number of carbonated drinks consumed and a significant reduction in the number of children becoming overweight or obese. ${ }^{8}$ Further anthropometric measures were taken two years after completion of the original project (three years after baseline) to assess any longitudinal effects.

\section{METHODS}

Two years after completion of the original project one investigator (IJ) took additional longitudinal measurements. She had also completed the original measurements and conducted the education programme. Because of lack of funding we were unable to collect further drink diaries at this time.

Several different methods are used to assess overweight and obesity in children. We defined overweight 
and obesity using the 1990 British centile charts, in which children above the 91 st centile are classified as overweight.

In the original project, the children in the three year groups attended junior schools in Christchurch, Dorset. Three years after baseline, the two older year groups had progressed to secondary schools and were tracked using school leaving lists. Most were attending three local secondary schools. From the original sample, 90 children had moved out of the area and 43 were attending secondary schools that were either outside of the project area or had fewer than six children from the original project attending. We traced 511 children from the original sample and carried out measurements on $434,67 \%$ of the original sample (figure).

\section{Outcome measures}

One investigator (IJ) took anthropometric measures of height (without shoes) to the nearest $0.1 \mathrm{~cm}$ using the Portable Leister height measure (Seca, Marsden) and weight (in light clothing) measured to the nearest $0.1 \mathrm{~kg}$ on medical scales (Seca 770, Marsden). We converted body mass index (weight $(\mathrm{kg}) /\left(\right.$ height $\left.(\mathrm{m})^{2}\right)$ ) to z scores (SD scores) and to centile values using the 1990 growth reference disc (Child Growth Foundation). ${ }^{9}$ The $z$ score (SD score) accounts for the child's age and sex and represents the deviation compared with an average child of the same sex and age. Waist circumference was measured at the point of flexure as the child bends to one side, with $1 \mathrm{~cm}$ deducted to account for clothing. Waist circumference was converted to $\mathrm{z}$ scores (SD scores) with the 2001 McCarthy references for waist circumference. $^{10}$ Our primary outcome measures were the change in BMI z score and the prevalence of overweight.

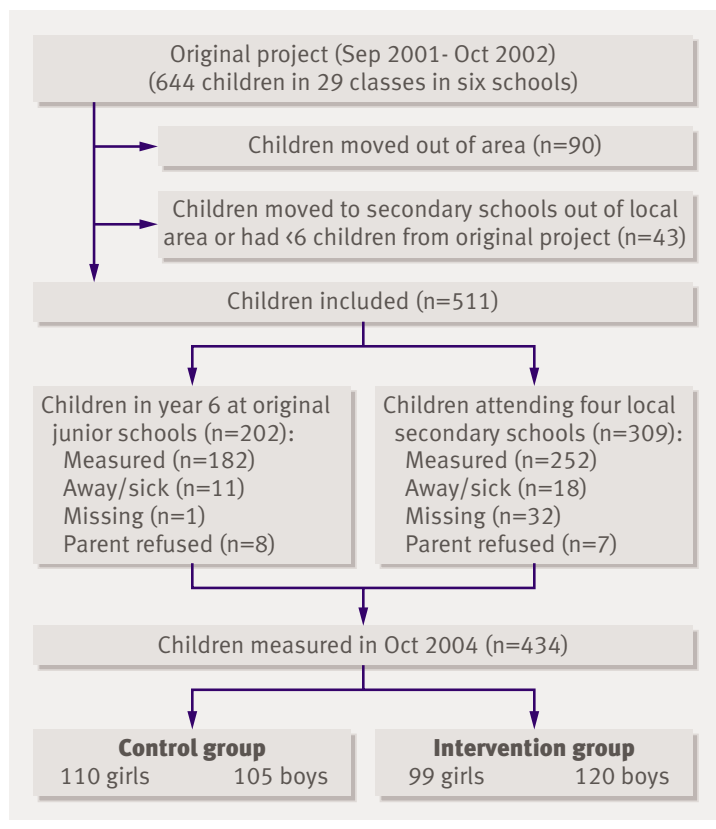

Trial profile for three year follow-up data
Statistical methods

The sample size of 376 calculated for the original project was based on changes in consumption of carbonated drinks. This sample size had $90 \%$ power to detect mean differences in $\mathrm{z}$ score (SD score) for BMIs of $0.49,0.42,0.35$, and 0.34 (assuming intracluster correlations of $0.1,0.05,0.01$, and 0.001 , respectively) between the intervention and control groups. As we were able to gather data on 434 children three years after baseline and using data from the 12 month follow-up we can refine this sample size calculation. In the original 12 month follow-up the intracluster correlation for the change in $\mathrm{z}$ score (SD score) over 12 months was -0.003 (assumed to be 0 ) and the $\mathrm{SD}$ was 0.44 in both groups combined. Thus at three years with a sample size of 434 and assuming an SD of 0.44 and an intracluster correlation coefficient of 0 , the study had $90 \%$ power to detect differences of 0.14 between control and intervention groups.

The original design was a cluster randomised controlled trial, with class being the cluster. Data were aggregated for each cluster and the two sets of clusters compared by using the independent samples $t$ test. Subsequently, because of the nature of the school environment and the progression of children to different schools, the clusters have not remained intact and some children were lost to follow-up. This resulted in some clusters having few children in them, and so reducing the validity of that method of analysis for the follow-up data. We therefore analysed the interval scaled data in this paper with MLwiN (version 2) using multilevel models to take into account variance within clusters. For binary data we implemented a logistic model using the same software. This has resulted in the 12 month analysis presented here not being identical to that in the original report. We used a 5\% significance level.

\section{RESULTS}

In the original project we collected baseline anthropometric measures from 644 children (321 girls). Of these, 434 children (209 girls) were re-measured three years later. There was no significant difference in the baseline $\mathrm{z}$ scores between children in the control and intervention groups who were present or missing at the final measurements. The average age was 8.6 (range 7.0-10.9) at the start of the project and 11.6 (10.0-13.9) at the three year follow-up.

Table 1 shows the BMIs, centile z scores (SD scores), and waist circumference $\mathrm{z}$ scores (SD scores) at baseline, 12 months, and three year follow-up. We also analysed data for each measure of change from baseline using baseline values, sex, and secondary school as covariates or cofactors. This made no material difference to the significance levels or mean changes between control and intervention group.

Table 2 shows the change in prevalence of overweight and obesity according to the 1990 British centile charts, with children above the 91 st centile classed as overweight. As previously reported, at 12 months there was a significant difference between the control 
Table 1 Change in body mass index (BMI), centile SD scores ( $\mathrm{z}$ scores), and waist SD scores ( $\mathrm{z}$ scores) at 12 months and 3 years after baseline

\begin{tabular}{|c|c|c|c|}
\hline & Control & Intervention & $\begin{array}{c}\text { Mean difference }(95 \% \mathrm{Cl}) \text {, } \\
\text { P value }\end{array}$ \\
\hline \multicolumn{4}{|l|}{ BMI* } \\
\hline Baseline $(n=486)$ & $17.5(2.36)$ & $17.2(2.14)$ & $\begin{array}{c}0.24(-0.16 \text { to } 0.64) \\
P=0.24\end{array}$ \\
\hline After 12 months $(n=474)$ & $18.3(2.85)$ & $17.8(2.45)$ & 0.59 (0.11 to 1.06$), P=0.02$ \\
\hline After 3 years $(n=434)$ & $19.7(3.36)$ & $19.0(3.21)$ & 0.68 (0.06 to 1.30$), P=0.03$ \\
\hline \multicolumn{4}{|c|}{ Change in BMI from baseline $†$} \\
\hline After 12 months ( $n=455)$ & $0.71(1.45)$ & $0.62(0.79)$ & $\begin{array}{c}0.10(-0.11 \text { to } 0.31) \\
P=0.36\end{array}$ \\
\hline After 3 years $(n=418)$ & $2.14(1.64)$ & $1.88(1.71)$ & $\begin{array}{c}0.26(-0.07 \text { to } 0.58), \\
P=0.12\end{array}$ \\
\hline \multicolumn{4}{|l|}{ Centile z score (SD score)* } \\
\hline Baseline $(n=486)$ & $0.53(0.98)$ & $0.44(0.98)$ & $\begin{array}{c}0.08(-0.09 \text { to } 0.26), \\
P=0.36\end{array}$ \\
\hline After 12 months ( $n=474)$ & $0.63(1.07)$ & $0.44(1.01)$ & 0.20 (0.01 to 0.38$), P=0.04$ \\
\hline After 3 years $(n=434)$ & $0.63(1.12)$ & $0.39(1.17)$ & 0.24 (0.02 to 0.46$), P=0.03$ \\
\hline \multicolumn{4}{|c|}{ Change in centile $z$ score (SD score) $\dagger$ from baseline } \\
\hline After 12 months ( $\mathrm{n}=455)$ & $0.05(0.57)$ & $0.03(0.30)$ & $\begin{array}{c}0.02(-0.06 \text { to } 0.11) \\
P=0.60\end{array}$ \\
\hline After 3 years $\ddagger(n=418)$ & $0.10(0.53)$ & $-0.01(0.58)$ & $\begin{array}{c}0.10(-0.00 \text { to } 0.21) \\
P=0.06\end{array}$ \\
\hline \multicolumn{4}{|c|}{ Waist circumference z score (SD score)* } \\
\hline Baseline $(n=486)$ & $0.85(0.94)$ & $0.83(0.91)$ & $\begin{array}{c}0.03(-0.14 \text { to } 0.19), \\
P=0.76\end{array}$ \\
\hline After 12 months $(n=474)$ & $0.99(0.93)$ & $0.88(0.87)$ & $\begin{array}{c}0.11(-0.05 \text { to } 0.27) \\
P=0.19\end{array}$ \\
\hline After 3 years $(n=434)$ & $0.96(1.22)$ & $0.80(1.07)$ & $\begin{array}{c}0.15(-0.06 \text { to } 0.37) \\
P=0.17\end{array}$ \\
\hline \multicolumn{4}{|c|}{ Change in waist circumference z score (SD score) from baseline } \\
\hline After 12 months ( $\mathrm{n}=455)$ & $0.08(0.64)$ & $0.08(0.47)$ & $\begin{array}{c}0.01(-0.09 \text { to } 0.12) \\
P=0.81\end{array}$ \\
\hline After 3 years $(n=418)$ & $0.099(0.99)$ & $0.01(0.66)$ & $\begin{array}{c}0.09(-0.06 \text { to } 0.26), \\
P=0.25\end{array}$ \\
\hline
\end{tabular}

*Based on maximum number of children in each cluster.

tBased on children with data at baseline and 12 months or 3 years.

$\ddagger$ Primary outcome.

and intervention groups but three years after baseline the difference was smaller and no longer significant.

\section{DISCUSSION}

A simple 12 month school based intervention focused on reducing consumption of carbonated drinks resulted in significant differences in the proportion of overweight children in the control and intervention groups. ${ }^{8}$ Two years after the completion of the study, however, the difference was no longer significant, and the number of overweight children had increased in

\begin{tabular}{|c|c|c|c|c|c|}
\hline & Control (\%) & $\begin{array}{l}\text { Intervention } \\
\text { (\%) }\end{array}$ & $\begin{array}{l}\text { Odds ratio } \\
(95 \% \mathrm{Cl})\end{array}$ & $P$ value & $\begin{array}{l}\text { Risk difference* } \\
(95 \% \mathrm{Cl})\end{array}$ \\
\hline Baseline $(n=486)$ & 20.6 & 17.4 & $\begin{array}{c}0.79(0.50 \text { to } \\
1.26)\end{array}$ & $\mathrm{P}=0.33$ & $\begin{array}{c}3.2 \%(-4.23 \% \text { to } \\
10.6 \%)\end{array}$ \\
\hline $\begin{array}{l}\text { After } 12 \text { months } \\
(n=474)\end{array}$ & 28.5 & 18.7 & $\begin{array}{c}0.58(0.37 \text { to } \\
0.89)\end{array}$ & $P=0.01$ & $\begin{array}{c}9.8 \%(1.83 \% \text { to } \\
17.8 \%)\end{array}$ \\
\hline $\begin{array}{l}\text { After } 3 \text { years } \uparrow \\
(n=434)\end{array}$ & 30.2 & 25.6 & $\begin{array}{c}0.79(0.52 \text { to } \\
1.21)\end{array}$ & $P=0.28$ & $\begin{array}{c}4.6 \%(-4.3 \% \text { to } \\
13.5 \%)\end{array}$ \\
\hline
\end{tabular}

${ }^{\star}$ Calculated assuming an intracluster correlation of 0 .

†Primary outcome. both groups, although the prevalence was still higher in the control group. In the three year follow-up, the only difference approaching significance was for the change in centile z score (SD score). Given the lack of a trend at 12 months this may well be a chance finding. The study had sufficient power to detect a difference of 0.14 or more, but the observed difference was only 0.10 . The study was originally powered to detect differences in consumption of carbonated drinks, and so we cannot rule out a type II error.

The original project was different from many other school based interventions in that the intervention was specific and promoted a healthy diet based on the balance of good health. It focused specifically on discouraging the consumption of carbonated drinks. Several recent studies have further confirmed the association between these drinks and obesity, ${ }^{11-15}$ as has a systematic review and meta-analysis of 88 studies. ${ }^{16}$ The role of these drinks as a causative agent of obesity is also recognised by the World Health Organization. ${ }^{17}$ One reason suggested for this association may relate to the high glycaemic index and that they provide "empty" calories. ${ }^{18}$ The physiological effect on satiety from energy ingested in liquid form is thought to be different from that from solid foods and this may in part be due to faster transit times and reduced gastric distension. ${ }^{19}$ Therefore the additional energy from these drinks may not be detected as easily by the body and individuals may not compensate for this additional energy by consuming less later. ${ }^{19}$

\section{Limitations}

A proportion of children were lost to follow-up; although $67 \%$ of the original cohort were measured at three years. Because of the natural progression of children at school, the original clusters did not remain intact and therefore we had to use a different method of analysis from the original study.

Unfortunately because of financial and time limitations we were not able to measure any further changes in consumption of carbonated drinks, or the socioeconomic status and pubertal status of these children.

The original project provided hope that a simple intervention could be beneficial in preventing obesity, but our new results show no effect two years after the end of the intervention. Evidence suggests that it would be beneficial for the whole population to decrease consumption of soft drinks, as these drinks have a high energy intake with little nutritional benefit. ${ }^{16}$ The recent UK obesity guidelines from the National Institute for Health and Clinical Excellence (NICE) highlight the important role that schools can play in promoting healthy lifestyles. ${ }^{20}$ Obesity is a complex condition, and another report suggests that specific interventions may ignore different interlinking influences. ${ }^{21}$ It remains unclear whether specific interventions or those that focus on all aspects of the diet and physical activity are the most successful. Perhaps the true impact of any school based intervention can effectively be evaluated only if the interventions are continuous. 


\section{WHAT IS ALREADY KNOWN ON THIS TOPIC}

The prevalence of childhood obesity is increasing

The UK government has set an ambitious target of halting the annual increase in childhood obesity by 2010

School based interventions show some success in prevention of obesity

\section{WHAT THIS STUDY ADDS}

The success of a school based intervention was not maintained two years after the end of the project
6 Sharma M. International school-based interventions for preventing obesity in children. Obes Rev 2006;7:261-9.

7 Summerbell CD, Waters E, Edmunds LD, Kelly S, Brown T, Campbell KJ. Interventions for preventing obesity in children. Cochrane Database Syst Rev 2005;(3):CD001871

8 James J, Thomas P, Cavan DA, Kerr D. Preventing childhood obesity by reducing consumption of carbonated drinks: cluster randomised controlled trial. BMJ 2004;328:1237-9.

9 Cole TJ, Freeman JV, Preece MA. Body mass index reference curves for the UK, 1990. BM/ 1995;73:25-9.

10 McCarthy HD, Jarrett KV, Crawley HF. The development of waist circumference percentiles in British children aged 5-16.9 yrs. Eur J Clin Nutr 2001;55:902-7.

11 Ebbeling CB, Feldman HA, Osganian SK, Chomitz VR, Ellenbogen SI, Ludwig DS. Effects of decreasing sugar-sweetened beverage consumption on body weight in adolescents: a randomized controlled pilot study. Pediatrics 2006;117:673-80.

We thank the headmasters, teachers, parents, and children at the participating schools. We also thank David Phillips for discussion and advice and Julia Knott for assistance with data entry.

Contributors: JJ and DK developed the original idea. JJ delivered the education programme, carried out the anthropometric measurements, and analysed the data. All authors contributed to writing the manuscript. PT provided statistical and methodological advice. DK directed the project and is guarantor. Funding: Internal resources within Bournemouth Diabetes and Endocrine Centre. IJ received a research scholarship from the Florence Nightingale Foundation (Band Trust Scholarship).

Competing interests: DK had a child attending one the schools involved in the original project.

Ethical approval: Dorset research and ethics committee approved the study. Provenance and peer review: Not commissioned; externally peer reviewed.

1 Lobstein T, Baur L, Uauy R. Obesity in children and young people: a crisis in public health. Obes Rev 2004;5:4-85.

2 World Health Organization. Global strategy on diet, physical activity and health: obesity and overweight. Geneva: WHO, 2006.

3 Jotangia D, Moody A, Stamatakis E, Wardle H. Obesity among children under 11. London: National Centre for Social Research, 2005.

4 Zaninotto P, Wardle H, Stamatakis E, Mindell J, Head J. Forecasting obesity to 2010. London: National Centre for Social Research/ Department of Health, 2006.

5 Story M. School-based approaches for preventing and treating obesity. Int J Obesity 1999;23:43-51 